\title{
Comparison of the polyphenolic profile and antibacterial activity of the leaves, fruits and flowers of Rhododendron ambiguum and Rhododendron cinnabarinum
}

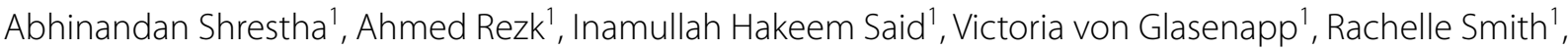 \\ Matthias S. Ullrich' ${ }^{1}$, Hartwig Schepker ${ }^{2}$ and Nikolai Kuhnert ${ }^{*}$
}

\begin{abstract}
Background: Rhododendron species have been traditionally used in countries like China, Nepal, Russia and North America for treating human diseases. These species are known to be a good source of polyphenolic plant secondary plant metabolites. They are known to have beneficial health properties for humans and have been used to treat diseases like asthma, skin diseases. In this contribution we investigate the phenolic profile and antibacterial activity of extracts from several plant organs including for the first time from leaves of different development stages.
\end{abstract}

Methods: In this study, the polyphenolic profile of fruits, flowers and leaves of different ages of Rhododendron ambiguum and Rhododendron cinnabarinum were studied by using HPLC-MS and compounds identified based on high resolution masses and identity of tandem mass spectra, UVNIS spectra and retention times if compared to standards.

Results: Fifty-nine different polyphenols including isomers were identified in these species by their fragmentation pattern and high resolution data. Also, the antibacterial activity of these parts (leaves, fruits and flowers) against grampositive bacteria was studied.

Conclusion: The leaves and fruits contained more polyphenols than the flowers. With the exception of flowers, the fruits and leaves of both species were also determined to have a significant antibacterial effect against four grampositive bacteria.

Keywords: Rhododendron, Polyphenols, Antibacterial, Leaves, Fruits, Flowers

\section{Background}

Polyphenols are secondary plant metabolites that are known to have different physical, chemical and biological properties. The four major types of polyphenols are flavonoids, phenolic acids, lignans and stilbenes. The phenolic acid polyphenols consist of the derivatives of hydroxybenzoic acid and hydroxycinnamic acid. The flavonoids are further classified into different groups based on their

\footnotetext{
*Correspondence: n.kuhnert@jacobs-university.de

1 Department of Life Science \& Chemistry, Jacobs University Bremen,

Campus Ring 1, 28759 Bremen, Germany

Full list of author information is available at the end of the article
}

structure variation and hydroxylation pattern. Proanthocyanidins (PAs) belong to the class of flavonoids, which are formed from the oligomerization and polymerization of flavan-3-ol units such as catechin and afzelechin (Fig. 1). PAs are commonly found in fruits, vegetables and grain $[1,2]$. They are known to have anti-inflammatory [3] and antimutagenic [4] effects and have been used in the treatment of asthma [4], skin diseases and UV radiations [5].

Rhododendron is a genus of woody plants that belong to Ericaceae family. Most of the species have attractive flowers and more than 1000 species of the genus have been described. They differ in their range of size, shape, 
<smiles>COc1cc(C(=O)O)ccc1OC1OC(CO)C(O)C(O)C1O</smiles>

Vanillic acid-O-hexoside $[2,3,4]$<smiles>O=c1c(OC2OCC(O)C(O)C2O)c(-c2cc(O)c(O)c(O)c2)oc2cc(O)cc(O)c12</smiles>

Myricetin-O-pentoside $[15,16,17]$<smiles>Oc1cc(O)c2c(c1)O[C@H](c1ccc(O)c(O)c1)[C@H](O)[C@H]2c1c(O)cc(O)c2c1O[C@H](c1ccc(O)c(O)c1)[C@H](O)C2</smiles>

Procyanidin B1 [39]<smiles>O=C(O)c1ccccc1OC1OC(CO)C(O)C(O)C1O</smiles>

Salicylic acid-O-hexoside $[5,6]$<smiles>O=c1c(OC2OC(CO)C(O)C(O)C2O)c(-c2ccc(O)c(O)c2)oc2cc(O)cc(O)c12</smiles>

Quercetin-O-hexoside [18, 19]<smiles>Oc1cc(O)c2c(c1)OC(c1ccc(O)c(O)c1)C(O)C2</smiles>

Fig. 1 Representative examples of polyphenols from Rhododendron species. For the complete list of structures of compounds identified, please refer to Additional file 1

texture, growth habit and color of blossoms [6]. The genus is ranging from shrubs and small to large trees. Rhododendron species have decorative flowers, which are mainly used for ornamental purposes. There is variation in the height of the plant, starting from $10 \mathrm{~cm}$ to $1 \mathrm{~m}$ (smallest species), while the example of largest specie is 
R. giganteum, which is almost $3 \mathrm{~m}$ tall. The leaves of most species are spirally arranged; the nature of leaves may be evergreen or deciduous.

The genus Rhododendron is found in almost all parts of the world except some parts in America and Africa. Species of the genus Rhododendron occur throughout the Northern Hemisphere and the Southern Hemisphere in South Eastern Asia and Northern Australasia. The plant is originally present in mountainous areas characterized by acidic well-drained soil, regular rainfall and cool summer temperatures [7]. On the other hand, majority of the genus prefers cooler temperature including the subgenus Hymenanthes. One of the subsections (Pontica) is indigenous to the areas outside the center of distribution and present in the areas of Japan, eastern China, Europe, North America and Russia [8].

Rhododendron (flowers and leaves) has traditionally been used in China, Nepal, North America, Russia, Korea, Austria and Romania for treating various diseases including arthritis, intestinal disorders, rheumatism, skin diseases, cough and other ailments [9]. They are known to be rich in polyphenolic compounds namely flavonoids and their glycosides, terpenoids and essential oils [1].

The new and exciting aspect of this study is the analysis of different plant organs where only limited data is available in the literature. The hypotheses of this study are that fruits, flowers and leaves have different polyphenolic profile and that the leaves of different ages, which are exposed to numerous environmental conditions might lead to the production of new compounds or variation in secondary metabolite quantities. In particular Rhododendron as an evergreen shrub grows a new generation of leaves every year offering the unique opportunity to compare the polyphenolic profile of leaves of different ages and hence study the biochemical history of the plant. Such an investigation has to the best of our knowledge never been carried out. The polyphenolic profile of the leaves of different age, flowers and fruits were analyzed for $R$. ambiguum and $R$. cinnabarinum. Both species belong to the subgenus Rhododendron, section Rhododendron. $R$. ambiguum and $R$. cinnabarinum belong to the subsection Triflora and Cinnabarina respectively. $R$. cinnabarinum is considered to be toxic for animals $[9,10]$. It is known from our previous studies that these two species out of 17 Rhododendron species showed higher activity against several Gram-positive bacteria [11]. Moreover, the high dose of both Rhododendron species exhibited a toxic effect in two mammalian cells and induced phenotypic changes that are characteristic for apoptosis [12]. Thus, the aim of the study was to analyze the chemical profile of Rhododendron crude extracts in order to contribute to our on-going investigations on the bioactivity potential of Rhododendron.

\section{Methods}

\section{Plant material and chemicals}

Fresh leaf material of $R$. ambiguum Hemsley and $R$. cinnabarinum Hooker (first, second, and third leaf) were collected from plants grown in the Rhododendron-Park Bremen (http://www.rhododendronparkbremen.de) from April 2013 at 10:00 [gene bank number: $R$. ambiguum (100.007); $R$. cinnabarinum (100.322)]. First and second year leaves were collected for $R$. ambiguum, and first, second and third year leaves were collected for $R$. cinnabarinum. The leaves were distinguished on the basis of their morphological features. Moreover, the flowers and fruits for both Rhododendron species were also sampled. Each sample species was collected from three different individual plants with the help of Dr. Hartwig Schepker. The identities of all plant species have been authenticated according to the German Genebank Rhododendron Database provided by the Bundessortenamt (http:// www.bundessortenamt.de/rhodo). Samples were deposited in herbaria with voucher numbers: $R$. ambiguum: OLD00801; R. cinnabarinum: OLD00757.

All chemicals (analytical grade) were purchased from Carl Roth (Karlsruhe, Germany). Standards were used whenever applicable, to compare the fragmentation and retention time of the compounds.

\section{Plant extraction}

The Rhododendron leaves, fruits and flowers were freeze dried using liquid nitrogen. A mortar and pestle was used to crush the dried brittle leaves. $2 \mathrm{~g}$ of the powdered material were dissolved in $10 \mathrm{~mL}$ of $80 \%$ aqueous methanol and for $24 \mathrm{~h}$ at $4{ }^{\circ} \mathrm{C}$. The mixture was then sonicated for $15 \mathrm{~min}$ and centrifuged at $3.220 \times g$ for $10 \mathrm{~min}$. The aliquot was then separated and stored at $-20{ }^{\circ} \mathrm{C}$ until further analyses.

\section{LC-ESI-TOF-MS (high resolution mass spectrometry)}

The LC equipment (Agilent 1200 series, Bremen, Germany) consists of a binary pump, an auto-sampler with $100 \mu \mathrm{L}$ loop and a UV-Vis detector with a light-pipe flow cell. The UV detector was used at $280 \mathrm{~nm}$ to measure the polyphenols. The $5 \mu \mathrm{m}$ diphenyl column having $250 \times 3 \mathrm{~mm}$ inner diameter (Varian, Darmstadt, Germany) was used for separation. This was connected to the microTOF mass spectrometer (Bruker Daltonics, Bremen, Germany) equipped with an electrospray ionization source. The internal calibration was achieved by using $0.1 \mathrm{M}$ sodium formate solution at $0.10 \mathrm{~mL} / \mathrm{min}$, which was injected through the six-port valve. The calibration was achieved by using the enhanced quadratic mode. Water/formic acid (1000:0.05 v/v) and methanol were used as solvent $A$ and $B$ respectively. The flow rate of the solvents was adjusted to $500 \mu \mathrm{L} / \mathrm{min}$. A linear 
gradient was used from $10 \%$ B to $80 \%$ B in 70 min and a further $10 \mathrm{~min}$ was assigned for the gradient to equilibrate from $80 \%$ B to $10 \%$ B for the next run. $3 \mu \mathrm{L}$ of the filtered extract was injected into the system. The software used in this system was Bruker Hystar.

\section{LC-ESI-MS ${ }^{n}$ (Tandem mass spectrometry)}

The Liquid chromatography equipment (Agilent 1100 series) comprises of a binary pump, an auto sampler having a $100 \mu \mathrm{L}$ capacity loop and a Diode Array Detector with a range from 200 to $600 \mathrm{~nm}$. The detector recorded at 254, 280 and $320 \mathrm{~nm}$, which is the best absorption wavelength for polyphenolic compounds. Chromatographic separation was performed using the same gradient method used in the LC-TOF analyses. A $5 \mu \mathrm{m}$ diphenyl column of $250 \times 3 \mathrm{~mm}$ i.d. (Varian, Darmstadt, Germany) with $500 \mu \mathrm{L} / \mathrm{min}$ flow rate of solvent was used. The LC equipment was connected with Ion-trap mass spectrometer, which was fitted with an ESI source (Bruker Daltonics HCT Ultra, Bremen, Germany) operating in full scan auto $\mathrm{MS}^{n}$ mode to obtain fragment ions. Tandem mass spectra were acquired in Auto-MS ${ }^{n}$ mode (smart fragmentation) using a ramping of the collision energy. Maximum fragmentation amplitude was fixed to $1 \mathrm{~V}$. MS operating conditions (negative mode) had been optimized with a capillary temperature of $365{ }^{\circ} \mathrm{C}$, a dry gas flow rate was of $10 \mathrm{~L} / \mathrm{min}$, and a nebulizer pressure of $10 \mathrm{psi} .3 \mu \mathrm{L}$ of the filtered extract was injected into the system. The software used in this system was Agilent Chemstation.

\section{Bacterial strains and antimicrobial susceptibility test}

Four Gram-Positive bacterial species i.e. Bacillus subtilis S168, Bacillus aquimaris MB-2011, Bacillus thioparus, and Clavibacter michiganensis and one Gram-Negative bacterial specie i.e. Escherichia coli were selected to compare the susceptibility of crude extracts of leaves, flower and fruit of two Rhododendron species i.e. R. ambiguum and $R$. cinnabarinum. Antimicrobial activity screening was conducted by the agar diffusion method [13]. Briefly, Lysogeny Broth (LB) agar plates were inoculated with $200 \mu \mathrm{L}$ of the inoculum of the tester organism $\left(1 \times 10^{7}\right.$ colony forming units per $\mathrm{mL}$ ) by evenly spreading the cell suspensions over the agar surface. Holes with diameters of $5 \mathrm{~mm}$ were punched into the agar plates. Subsequently, $50 \mu \mathrm{L}$ of the plant crude extracts were filled into each well. The plates were incubated overnight at $28{ }^{\circ} \mathrm{C}$. Inhibition of microbial growth was determined by measuring the radius of the inhibition zone. For each bacterial strain, $80 \%$ aqueous methanol solutions were used as negative solvent controls. All experiments were performed in triplicates and the results were presented as mean values. Ampicillin was used as the positive control and the extraction solvent, $80 \%$ aqueous methanol was used as the negative control.

\section{Results and discussion}

To our knowledge, no investigation on the polyphenolic profile of leaves of different ages has been carried out. The crude extracts of all parts of the two selected species $R$. ambiguum and $R$. cinnabarinum (i.e. first, second, third leaves, flowers and fruits) were extracted with $80 \%$ aqueous methanol in order to extract polyphenols. Both species were recently shown to possess promising biological activities [11] and their plants consisted of leaves of different age. These extracts were analyzed by reversed phase HPLC using a diphenyl column with a gradient using methanol and water/formic acid (1000:0.05 v/v). Negative ion mode was used to study the polyphenols using tandem mass spectrometry and high resolution mass spectrometry. The compounds were identified in the high resolution mass data by observing an absolute mass error below $5 \mathrm{ppm}$ for their elemental composition. The UV spectrum at $280 \mathrm{~nm}$ was used to identify the PAs present in the samples. Also, the fragmentation pathway of PAs by heterocyclic ring fission (HRF) and retroDiels-Alder (RDA) reaction were considered [14].

\section{Total ion chromatograms from LC-MS}

The chromatograms of Rhododendron cinnabarinum first year leaves, second year leaves, third year leaves, flowers and fruits were directly compared and are shown in Fig. 2. The chromatograms of the first, second and third year leaves consisted of peaks at identical retention time and comparable intensities. The chromatograms of flowers and fruits were different compared to the leaves. The chromatogram of flowers consisted of peaks with lower intensity in the region $0-30 \mathrm{~min}$, which suggests that the hydrophilic compounds are present in lower intensity compared to the leaves. However, after $30 \mathrm{~min}$, the chromatogram of the flowers was similar to the leaves. On the other hand, the chromatogram of the fruits exhibited additional peaks not present in the leaves and flowers.

In this study, 59 polyphenolic compounds were identified from both Rhododendron species for the first, second third year leaves, flower and fruit (Table 1). The identification of reported compounds was based on their retention time, fragmentation pattern and high resolution mass data. All identified polyphenol compounds have been discovered in nature already $[1,15-26]$. Out of the identified compounds, 46 were already reported to be found in Rhododendron species [1, 16-18]. In this study, 13 new polyphenolic compounds were identified in Rhododendron species. The fruits consisted of the highest 


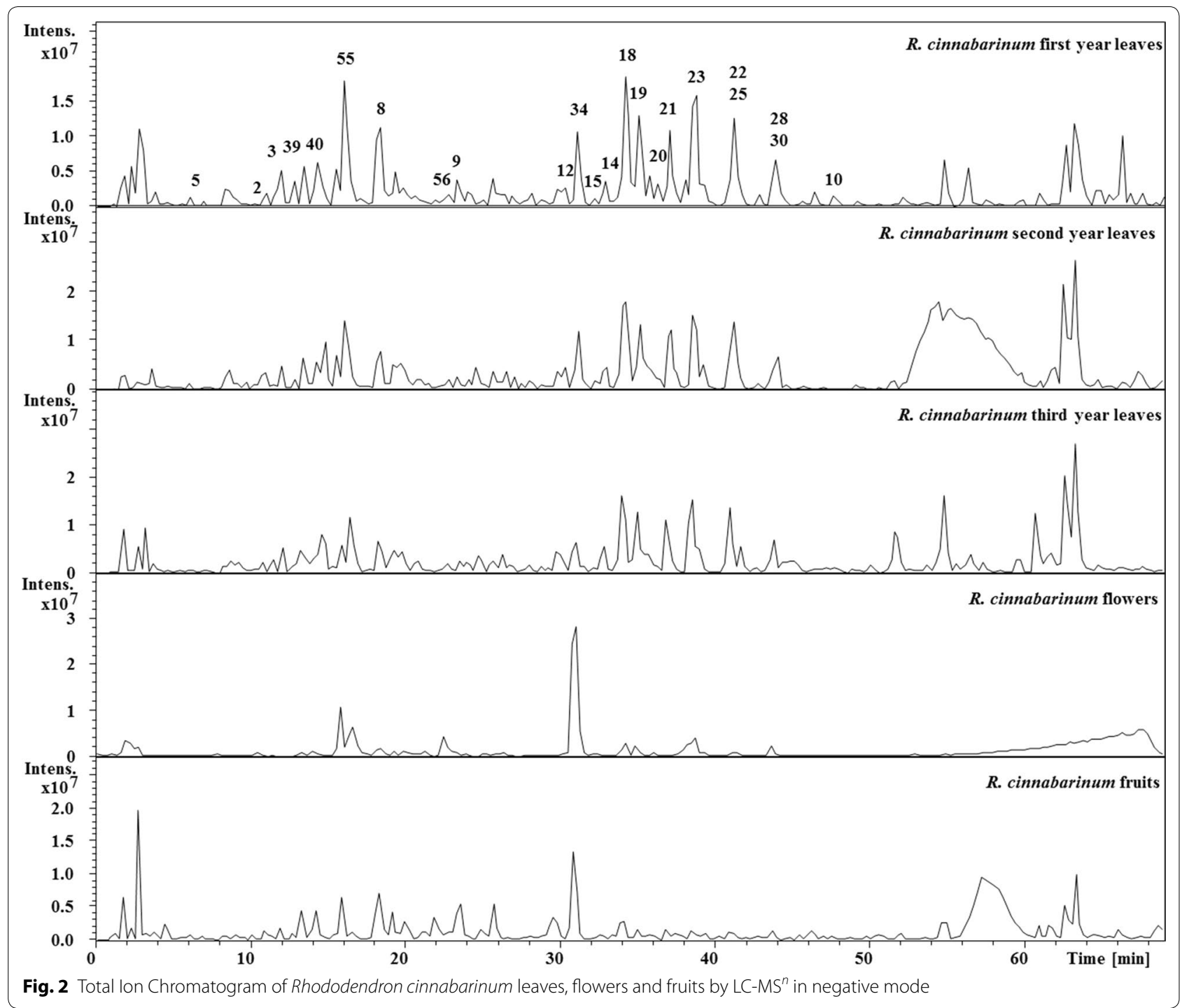

variety and concentration of PAs among the four parts of $R$. ambiguum and $R$. cinnabarinum.

\section{Characterization of methyl gallate hexoside [1] $\left(M_{\mathrm{r}} 345\right)$}

A peak was detected at $m / z 345$ and was assigned to be methyl gallate hexoside. The peak produced the fragmentation with base peak at $m / z 183$ and secondary peaks of $m / z 168$ and 124 .

\section{Characterization of (epi)catechin-(4,8'/2,6')-(epi)catechin $[53,54]\left(M_{\mathrm{r}} 576\right)$}

Two peaks were detected at $m / z 575$ and were assigned as A-type dimer of (epi)catechin unit. The first peak produced an $\mathrm{MS}^{2}$ base peak of $m / z 449$ and secondary peak of $m / z 287$. The second peak produced an $\mathrm{MS}^{2}$ base peak of $m / z 423$ and secondary peak of $m / z 285$.
Characterization of catechin [55] and epicatechin [56] $\left(M_{\mathrm{r}}\right.$ 290)

Two peaks were detected at $m / z 289$. The first peak was assigned as catechin and the second peak was assigned as epicatechin based on their polarity. Both peaks produced similar fragmentation, consisting of an $\mathrm{MS}^{2}$ base peak of $m / z 245$ and secondary peak of $m / z 203$.

\section{Characterization of gallocatechin [57] and epigallocatechin [58] $\left(M_{\mathrm{r}}\right.$ 306)}

Two peaks were detected at $m / z$ 305. The first peak was assigned as gallocatechin and the second peak was assigned as epigallocatechin based on their polarity. Both peaks produced similar fragmentation, consisting of an MS $^{2}$ base peak of $\mathrm{m} / z 179$ and secondary peak of $\mathrm{m} / \mathrm{z}$ 164. 
Table 1 Polyphenols present in different year leaves, flowers and fruits of R. ambiguum and R. cinnabarinum

\begin{tabular}{|c|c|c|c|c|c|c|c|c|c|c|c|c|c|}
\hline \multirow[t]{3}{*}{ No. } & \multirow{3}{*}{$\begin{array}{l}\text { Species } \\
\text { Part } \\
\text { Compound }\end{array}$} & \multirow[t]{3}{*}{ References } & \multirow[t]{3}{*}{$m / z[M-H]^{-}$} & \multirow[t]{3}{*}{ RT } & \multicolumn{4}{|c|}{ R. ambiguum } & \multicolumn{5}{|c|}{ R. cinnabarinum } \\
\hline & & & & & \multirow[t]{2}{*}{$1 \mathrm{st}$} & \multirow[t]{2}{*}{ 2nd } & \multirow[t]{2}{*}{ FI. } & \multirow[t]{2}{*}{ Fr. } & \multirow[t]{2}{*}{$1 \mathrm{st}$} & \multirow[t]{2}{*}{ 2nd } & \multirow[t]{2}{*}{$3 r d$} & \multirow[t]{2}{*}{ FI. } & \multirow[t]{2}{*}{ Fr. } \\
\hline & & & & & & & & & & & & & \\
\hline 1 & Methyl gallate hexoside & {$[35]$} & 345.0827 & 11.8 & & Y & & & & & & & \\
\hline 2 & Vanillic acid-O-hexoside & [19] & 329.0864 & 10.2 & & Y & Y & Y & Y & Y & Y & Y & Y \\
\hline 3 & Vanillic acid-O-hexoside & [19] & 329.0867 & 11.7 & Y & Y & Y & Y & Y & Y & & & Y \\
\hline 4 & Vanillic acid-O-hexoside & [19] & 329.0864 & 13.9 & & & & & Y & Y & Y & Y & \\
\hline 5 & Salicylic acid-O-hexoside & {$[20]$} & 299.0761 & 6.3 & & Y & & & Y & Y & Y & Y & Y \\
\hline 6 & Salicylic acid-O-hexoside & {$[20]$} & 299.0762 & 8.5 & & & & & & Y & & & \\
\hline 7 & 3-O-Caffeoylquinic acid & {$[1]$} & 353.0877 & 13.0 & Y & Y & Y & Y & & & Y & & \\
\hline 8 & 5-O-Caffeoylquinic acid & [1] & 353.0873 & 18.2 & & Y & Y & Y & Y & Y & Y & & Y \\
\hline 9 & 4-O-Caffeoylquinic acid & {$[1]$} & 353.864 & 23.0 & & Y & & & Y & Y & Y & & \\
\hline 10 & Naringenin & {$[29]$} & 271.0602 & 47.9 & Y & Y & & Y & Y & & & Y & Y \\
\hline 11 & Myricetin & {$[29]$} & 317.0296 & 38.9 & Y & Y & Y & Y & & & & & Y \\
\hline 12 & Myricetin-O-hexoside & {$[1]$} & 479.0820 & 30.8 & & & Y & Y & Y & Y & Y & & Y \\
\hline 13 & Myricetin-O-hexoside & {$[1]$} & 479.0853 & 35.3 & Y & Y & Y & Y & & & & & \\
\hline 14 & Myricetin-O-rhamnoside & {$[1]$} & 463.0899 & 33.0 & & & & & Y & Y & Y & & Y \\
\hline 15 & Myricetin-O-pentoside & [1] & 449.0728 & 32.1 & & & & Y & Y & Y & Y & & Y \\
\hline 16 & Myricetin-O-pentoside & [1] & 449.0725 & 37.8 & & & & Y & Y & Y & & & \\
\hline 17 & Myricetin-O-pentoside & {$[1]$} & 449.0732 & 39.1 & Y & Y & Y & Y & & & & & \\
\hline 18 & Quercetin-O-hexoside & {$[1]$} & 463.0898 & 34.2 & Y & Y & Y & Y & Y & Y & Y & Y & Y \\
\hline 19 & Quercetin-O-hexoside & {$[1]$} & 463.0897 & 35.5 & Y & Y & & Y & & Y & Y & Y & Y \\
\hline 20 & Quercetin-O-pentoside & [1] & 433.0771 & 36.6 & Y & Y & & & Y & Y & Y & & \\
\hline 21 & Quercetin-O-pentoside & [1] & 433.0795 & 37.4 & Y & Y & Y & Y & Y & Y & Y & Y & Y \\
\hline 22 & Quercetin-O-pentoside & {$[1]$} & 433.0798 & 41.2 & Y & Y & Y & Y & Y & Y & Y & Y & Y \\
\hline 23 & Quercetin-O-rhamnoside & {$[1]$} & 447.0921 & 38.7 & Y & Y & Y & Y & Y & Y & Y & Y & Y \\
\hline 24 & Quercetin-O-rhamnoside-O-hexoside & {$[1]$} & 609.1442 & 34.3 & Y & Y & & & Y & Y & & & \\
\hline 25 & Quercetin-O-glucoronide & {$[21]$} & 477.0676 & 40.8 & & & & & & Y & Y & & Y \\
\hline 26 & Quercetin & {$[1]$} & 301.0342 & 44.4 & Y & Y & Y & Y & & Y & & & \\
\hline 27 & Kamepferol & {$[29]$} & 285.0414 & 49.5 & Y & Y & Y & Y & & & & & \\
\hline 28 & Kaempferol-3-O-rhamnoside & {$[22]$} & 431.0982 & 43.6 & Y & Y & Y & & Y & Y & Y & Y & Y \\
\hline 29 & Kaempferol-3-O-pentoside & {$[22]$} & 417.0827 & 41.0 & & Y & Y & Y & & & & & \\
\hline 30 & Kaempferol-3-O-pentoside & {$[22]$} & 417.0833 & 43.9 & & Y & Y & Y & Y & Y & Y & Y & Y \\
\hline 31 & Kaempferol-3-O-glucoronide & {$[23]$} & 461.0719 & 43.6 & & & & & & Y & & & \\
\hline 32 & Taxifolin & {$[36]$} & 303.0507 & 29.1 & & Y & Y & & & & & & \\
\hline 33 & Taxifolin-O-pentoside & [1] & 435.0936 & 27.8 & Y & Y & & Y & & & & & Y \\
\hline 34 & Taxifolin-O-pentoside & {$[1]$} & 435.0936 & 31.1 & Y & Y & Y & Y & Y & Y & Y & Y & Y \\
\hline 35 & Taxifolin-O-pentoside & {$[1]$} & 435.0930 & 33.6 & & Y & & & & & & & \\
\hline 36 & (Epi)gallocatechin-(epi)gallocatechin & {$[1]$} & 609.1259 & 6.5 & & & & Y & & & & & Y \\
\hline 37 & (Epi)gallocatechin-(epi)gallocatechin & {$[1]$} & 609.1246 & 7.5 & & & & Y & & & & & \\
\hline 38 & (Epi)gallocatechin-(epi)gallocatechin & {$[1]$} & 609.1251 & 10.2 & & & & Y & & & & & \\
\hline 39 & (Epi)catechin-(epi)catechin (Procyanidin dimer B1) & {$[1]$} & 577.1372 & 13.4 & Y & Y & Y & Y & Y & Y & Y & Y & Y \\
\hline 40 & (Epi)catechin-(epi)catechin (Procyanidin dimer B) & {$[1]$} & 577.1377 & 14.3 & Y & Y & Y & Y & Y & & Y & Y & Y \\
\hline 41 & (Epi)catechin-(epi)catechin (Procyanidin dimer B) & {$[1]$} & 577.1373 & 18.6 & & & Y & Y & & & & Y & Y \\
\hline 42 & (Epi)catechin-(epi)catechin (Procyanidin dimer B2) & {$[1]$} & 577.1367 & 20.3 & & Y & Y & Y & Y & Y & Y & Y & Y \\
\hline 43 & (Epi)catechin-(epi)catechin (Procyanidin dimer B) & [1] & 577.1358 & 23.1 & & & Y & Y & Y & Y & Y & & Y \\
\hline 44 & Procyanidin Trimer C & [24] & 865.1994 & 5.6 & & Y & & Y & Y & Y & Y & & Y \\
\hline 45 & Procyanidin Trimer C & [24] & 865.1953 & 25.6 & & & & Y & & & & & \\
\hline 46 & A type Procyanidin Trimer C & [24] & 863.1805 & 22.2 & & & & & Y & Y & Y & Y & Y \\
\hline 47 & (Epi)gallocatechin-(epi)catechin & [1] & 593.1310 & 7.7 & & & & Y & Y & Y & & & Y \\
\hline
\end{tabular}


Table 1 continued

\begin{tabular}{|c|c|c|c|c|c|c|c|c|c|c|c|c|c|}
\hline \multirow[t]{3}{*}{ No. } & \multirow{3}{*}{$\begin{array}{l}\text { Species } \\
\text { Part } \\
\text { Compound }\end{array}$} & \multirow[t]{3}{*}{ References } & \multirow[t]{3}{*}{$m / z[M-H]^{-}$} & \multirow[t]{3}{*}{ RT } & \multicolumn{4}{|c|}{ R. ambiguum } & \multicolumn{5}{|c|}{ R. cinnabarinum } \\
\hline & & & & & $1 \mathrm{st}$ & 2nd & FI. & Fr. & $1 s t$ & 2nd & 3rd & FI. & Fr. \\
\hline & & & & & & & & & & & & & \\
\hline 48 & (Epi)gallocatechin-(epi)catechin & [1] & 593.1309 & 9.7 & & & Y & Y & Y & Y & Y & & Y \\
\hline 49 & (Epi)gallocatechin-(epi)catechin & [1] & 593.1314 & 10.5 & & & & Y & & & & & Y \\
\hline 50 & (Epi)gallocatechin-(epi)catechin & [1] & 593.1307 & 12.6 & & & & Y & & & & & Y \\
\hline 51 & (Epi)gallocatechin-(epi)catechin & [1] & 593.1323 & 13.7 & & & Y & Y & & & & & Y \\
\hline 52 & (Epi)gallocatechin-(epi)catechin & [1] & 593.1311 & 18.2 & & & & Y & & & & & \\
\hline 53 & (Epi)catechin-(4,8/2,6)-(epi)catechin & [1] & 575.1209 & 27.2 & Y & Y & Y & Y & & & & & Y \\
\hline 54 & (Epi)catechin-(4,8/2,6)-(epi)catechin & [1] & 575.1201 & 32.4 & Y & Y & Y & Y & & & & & Y \\
\hline 55 & Catechin & [1] & 289.0721 & 16.0 & Y & Y & Y & Y & Y & Y & Y & Y & Y \\
\hline 56 & Epicatechin & [1] & 289.0713 & 23.0 & Y & Y & Y & Y & Y & & & Y & \\
\hline 57 & Gallocatechin & [1] & 305.0656 & 8.5 & & Y & Y & Y & & & & & Y \\
\hline 58 & Epigallocatechin & {$[1]$} & 305.0660 & 15.4 & & Y & Y & Y & & & & & \\
\hline 59 & (Epi)catechin-O-D-glucopyranoside & {$[25]$} & 451.1258 & 10.5 & & & & & Y & $Y$ & $Y$ & & $Y$ \\
\hline
\end{tabular}

$R T$ retention time, Fl. flowers, Fr. Fruits, 1st, 2nd, 3rd 1st, 2nd, 3rd year leaves

Characterization of (epi)catechin-(4,8')-(epi)catechin [39, 40, 41, 42, 43] $\left(M_{\mathrm{r}}\right.$ 578)

Five peaks were detected at $m / z 577$. They were assigned as the PA dimer. All the peaks produced similar fragmentation with the base peak of $m / z 407$ and secondary peaks of $\mathrm{m} / z$ 425 and 285. The standards of the dimers B1 and B2 were used to differentiate the isomers by their retention time.

\section{Characterization of (epi)gallocatechin-(4,8')-(epi)catechin and (epi)catechin-(4,8')-(epi)gallocatechin [47, 48, 49, 50, 51, 52] $\left(M_{\mathrm{r}}\right.$ 594)}

Six peaks were detected at $m / z 593$. They were speculated to be dimeric B-type PA consisting of (epi)catechin and (epi)gallocatechin monomeric units. All the peaks produced similar fragmentation having the base peak of $m / z 425$ and secondary peak of $m / z 407$.

\section{Characterization of (epi)gallocatechin-(4,8')-(epi) gallocatechin $[36,37,38]\left(M_{r} 610\right)$}

Three peaks were detected at $m / z 609$ and were speculated to be dimeric B-type PAs with (epi)gallocatechin monomeric units. The three peaks produced the fragmentation with base peak at $m / z 423$ and secondary peaks of $m / z 441$ and 283 .

\section{Characterization of Taxifolin [27] $\left(M_{\mathrm{r}}\right.$ 304)}

A peak was detected at $m / z 303$ and was assigned to be taxifolin. The peak produced the fragmentation with base peak at $m / z 285$ and secondary peaks of $m / z 177$ and 125 .

\section{Identification of other polyphenols}

The polyphenols were identified by their specific fragmentation patterns, retention time and high resolution mass values. The other polyphenols that were identified in the leaf extracts are three vanillic acid-O-hexosides [19], two salicylic acid hexosides $[20,28]$, three caffeoylquinic acids [1], naringenin [29], myricetin [29], two myricetin-O-hexosides [1], myricetin-O-rhamnoside [1], three myricetin$O$-pentosides [1], two quercetin- $O$-hexosides [1], three quercetin- $O$-pentosides [1], quercetin-O-rhamnoside [1], quercetin- $O$-rhamnoside- $O$-hexoside [1], quercetin$O$-glucoronide [21, 30], quercetin [1], kaempferol [27, 29], kaempferol-O-rhamnoside [22], two kaempferol-O-pentosides [22], kaempferol-O-glucoronide [23, 30], three taxifolin- $O$-pentosides $[1,31]$, two procyanidin trimers $\mathrm{C}$ $[25,32]$, one A-type procyandintrimer $C[21,24]$ and (epi) catechin-O-D-glycopyranoside [25]. The tandem mass spectra of some compounds are shown in Fig. 3.

\section{Antibacterial activity}

Four Gram-positive organisms were used to compare the antibacterial activity of different plant parts of two species from genus Rhododendron. Crude extract of first, second, third year leaves in addition to flowers and fruits of $R$. ambiguum and $R$. cinnabarinum were obtained using $80 \%$ methanol. There was no bioactivity observed for crude extracts of all samples against Escherichia coli. Against Gram-positive bacteria, the bioactivity of R. ambiguum ranged between 0.5 and $0.7 \mathrm{~cm}$, while for R. cinnabarinum between 0.5 and $0.8 \mathrm{~cm}$ (Fig. 4). Antibacterial effects of fruit and leaves extracts were in the same order of magnitude. However, there was a reduced antibacterial activity observed for the flowers of $R$. cinnabarinum and $R$. ambiguum. This could be due to the evolutionary aspect as flowers have a short blooming period in a year compared to the leaves and fruits. In general, $B$. 


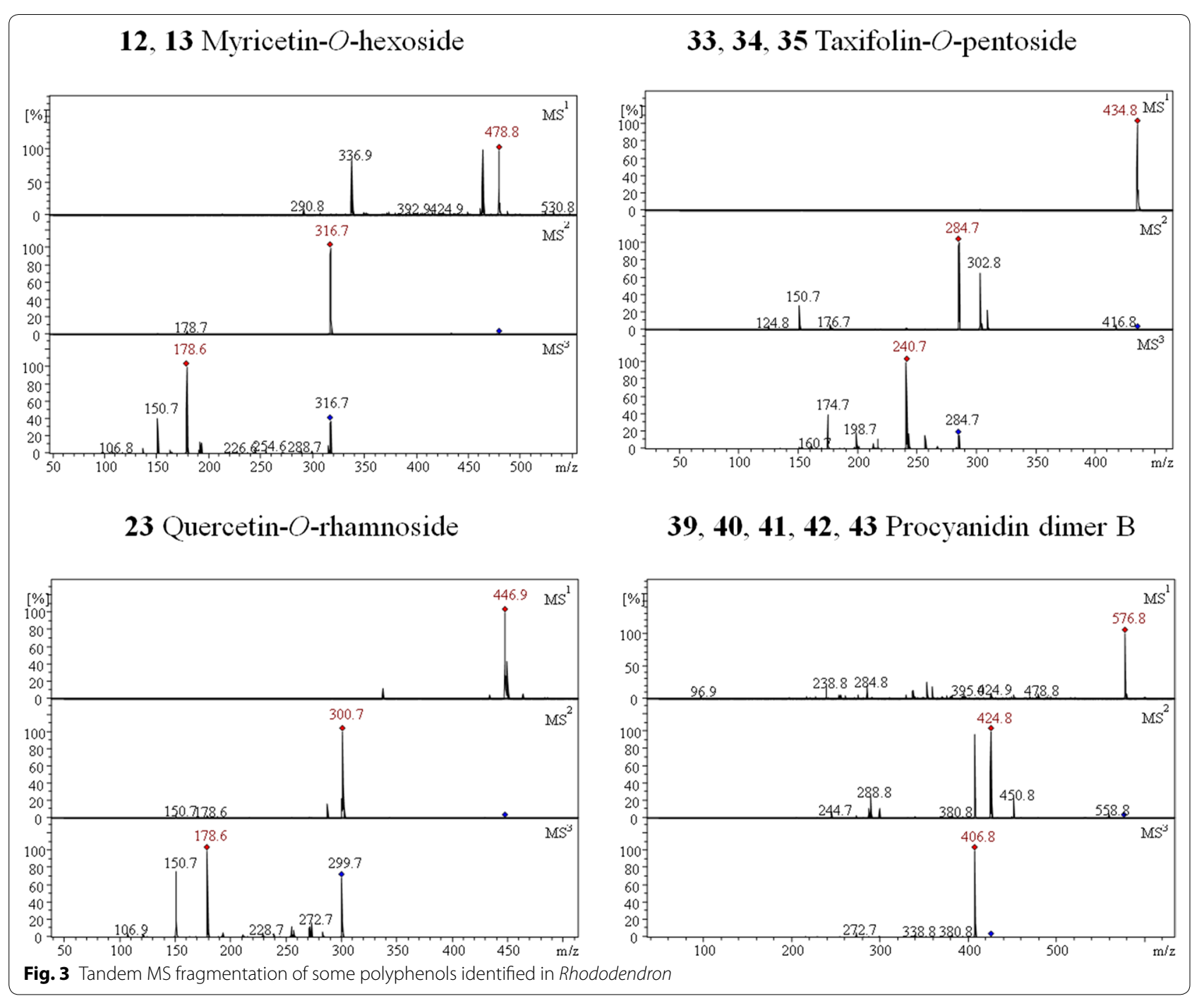

thioparus was the most sensitive bacteria species towards the plant parts for both Rhododendron species. These results are in agreement with our previous study, which showed a higher antibacterial effect of Rhododendron species against Gram-positive and higher effect for $R$. cinnabarinum [11]. The polyphenolic analysis indicated that Taxifolin derivatives were present in high concentration in the leaves of both plant species, which could be the reason of apoptosis like phenotype observed before in other studies [12]. Moreover, this finding is also supported by other studies, which reported the effect of Taxifolin in different cancer cell lines by inducing apoptosis cell death [33, 34].

The radius of the inhibition zones was measured in triplicates and the values are given as means \pm standard deviations. The aqueous methanol used as negative controls did not yield inhibition zones (data not shown).

Since flowers were found to have lower bioactivity as compared to the leaves and fruits, a list of compounds present in either leaves or fruits, but not in flowers was compiled. This list consisted of $\mathbf{1}$ (methyl gallate hexoside), 6 (salicylic acid- $O$-hexoside), 9 (4-O-caffeoylquinic acid), 14 (myricetin-O-rhamnoside), 15, 16 (myricetin-O-pentoside), 20 (quercetin- $O$-pentoside), 24 (quercetin-O-rhamnoside-O-hexoside), 31 (kaempferol-3-O-glucuronide), 33, 35 (taxifolin- $O$-pentoside), 36, 37, 38 (epi)gallocatechin-(epi)gallocatechin, 44, 45 (procyanidin trimer $\mathrm{C}$ ), 47, 49, 50, 52 ((epi)gallocatechin(epi)catechin) and 59 ((epi)catechin-O-D-glucopyranoside). The presence of these compounds in the plant 


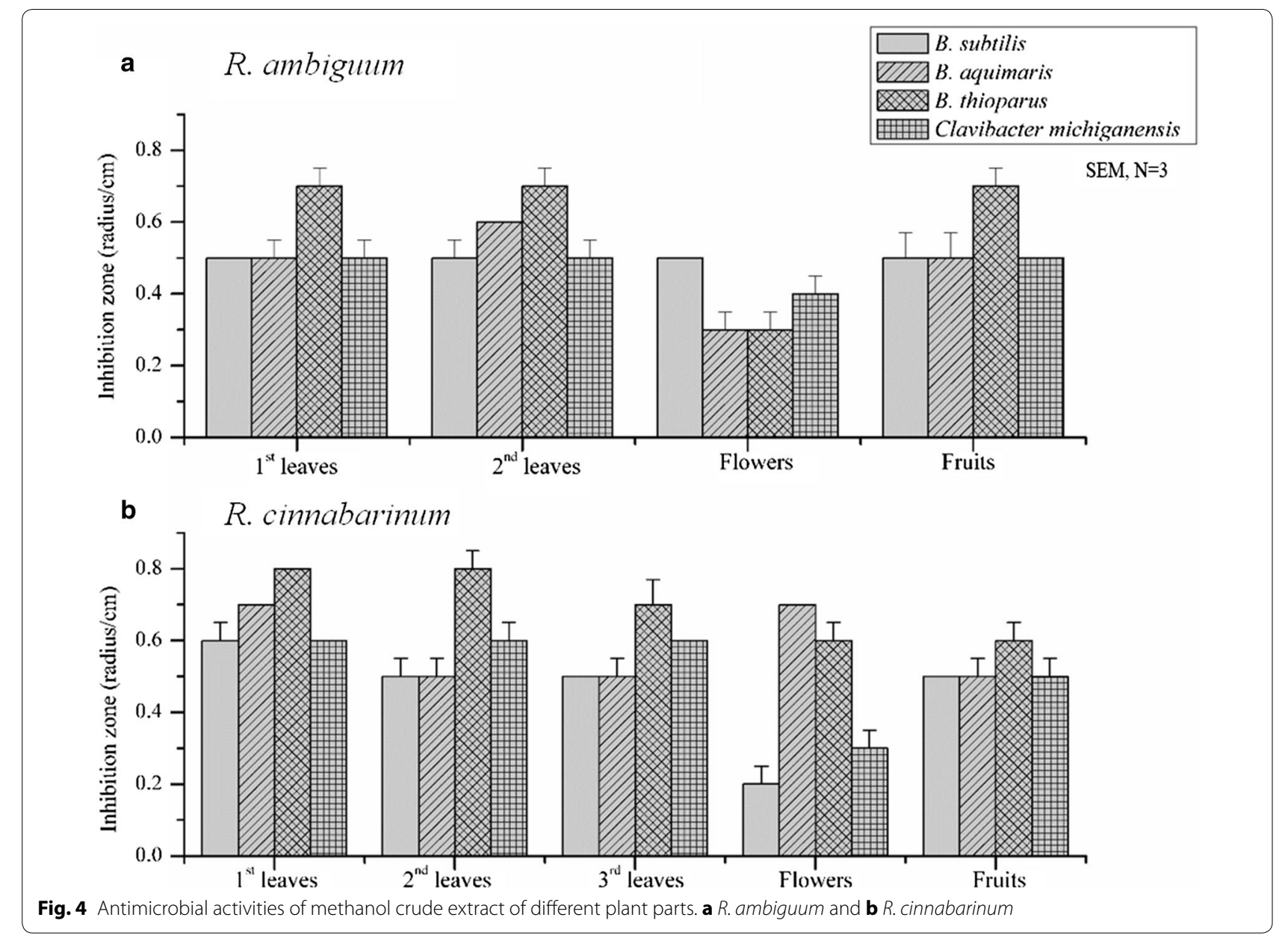

organs could be either a contributing factor to the bioactivity itself or could function as a marker for plant organs with potential bioactivity.

\section{Conclusions}

The different parts of the R. ambiguum and R. cinnabarinum are a rich source of polyphenols. Fifty-nine different types of polyphenols including isomers were identified in these parts based on their fragmentation pattern and high resolution mass spectra in negative ion mode. The polyphenolic profile of different year leaves was found to be similar. Among all the parts, the fruits were found to contain the highest variety and concentration of polyphenols. PAs were mainly found in the fruits. However, there are many unidentified compounds present in leaves, flowers and fruits, which need to be analyzed in future. We can conclude that both Rhododendron species have antibacterial effect towards Gram-positive bacteria, while there was no significant difference between different seasonal leaves and fruits, but low effect for flowers.

\section{Additional file}

Additional file 1: Figure A1. Total lon Chromatogram of Rhododendron ambiguum first year leaves, second year leaves, flowers and fruits generated by LC-MS ${ }^{n}$ in negative mode. Figure A2. Structures of all identified compounds in Rhododendron ambiquum and Rhododendron cinnabarinum. Table A1. Fragmentation pattern of the identified compounds in Rhododendron ambiguum and Rhododendron cinnabarinum.

\section{Abbreviations}

ESI: electro spray ionization; HPLC: high performance liquid chromatography; LB: Lysogeny Broth; LC: liquid chromatography; $\mathrm{m} / \mathrm{z}$ : mass to charge ratio; M: molar; $\mathrm{M}_{\mathrm{r}}$ : molecular weight; MS: mass spectrometry; $\mathrm{MS}^{n}$ : tandem mass spectrometry; PAs: proanthocyanidins; psi: pound-force per square inch; RT: retention time; TOF: time of flight; UV: ultra violet; $v / \mathrm{v}$ : volume/volume; Vis: visible.

\section{Authors' contributions}

AS and AR designed experiments, conducted the experimental work, and prepared the manuscript; IHS, VVG and RS also helped AS to conduct the experimental work and analyze the data. HS collected, identified and prepared plant materials. NK and MU organized, discussed and supervised the project and contributed to manuscript writing. All authors read and approved the final manuscript. 


\section{Author details}

1 Department of Life Science \& Chemistry, Jacobs University Bremen, Campus Ring 1, 28759 Bremen, Germany. ${ }^{2}$ Stiftung Bremer Rhododendronpark, Deliusweg 40, 28359 Bremen, Germany.

\section{Acknowledgements}

The authors would like to thank Ms. Anja Müller for the technical support and Dr. Hartwig Schepker for providing the Rhododendron material and their complete botanical information.

\section{Competing interests}

The authors declare that they have no competing interests.

\section{Availability of data and materials}

A supplement titled "Additional file 1.docx" has been uploaded along with the manuscript, which includes the chromatogram of the different parts of R. ambiguum, the structures and fragmentation patterns of all compounds identified in this study.

\section{Consent to publish}

The authors hereby consent to the publication of the manuscript in the journal BMC Research Notes.

\section{Funding}

The authors would like to thank Rhododendron Park and Jacobs University for their financial support.

\section{Publisher's Note}

Springer Nature remains neutral with regard to jurisdictional claims in published maps and institutional affiliations.

Received: 11 February 2016 Accepted: 7 July 2017

Published online: 20 July 2017

\section{References}

1. Jaiswal R, Jayasinghe $L$, Kuhnert N. Identification and characterization of proanthocyanidins of 16 members of the Rhododendron genus (Ericaceae) by tandem LC-MS. J Mass Spectrom. 2012;47(4):502-15.

2. Kuhnert N, Karakoese H, Jaiswal R. Analysis of chlorogenic acids and other hydroxycinnamates in food, plants, and pharmacokinetic studies. In: Anonymous, editor. Boca Raton: CRC Press; 2012. p. 461-510.

3. Kruger MJ, Davies N, Myburgh KH, Lecour S. Proanthocyanidins, anthocyanins and cardiovascular diseases. Food Res Int. 2014;59:41-52.

4. Zhou DY, Du Q, Li RR, Huang M, Zhang Q, Wei GZ. Grape seed proanthocyanidin extract attenuates airway inflammation and hyperresponsiveness in a murine model of asthma by downregulating inducible nitric oxide synthase. Planta Med. 2011;77(14):1575-81.

5. Deters A, Dauer A, Schnetz E, Fartasch M, Hensel A. High molecular compounds (polysaccharides and proanthocyanidins) from Hamamelis virginiana bark: influence on human skin keratinocyte proliferation and differentiation and influence on irritated skin. Phytochemistry. 2001;58(6):949-58.

6. Dirr MA. Manual of woody landscape plants: their identification, ornamental characteristics, culture, propagation and uses. 4th ed. Champaign; 2009.

7. Horn CN. Distribution and ecological preference of Rhododendron eastmanii Kron \& Creel (May-White Azalea) in South Carolina. Castanea. 2005;70(1):1-12.

8. Chamberlain DF, Tian-Lu M. The distribution of Rhododendron subgenus Hymenanthes with special reference to Yunnan (W China). Notes RBG Edinburgh. 1985;43(1):7-13.

9. Popescu R, Kopp B. The genus Rhododendron: an ethnopharmacological and toxicological review. J Ethnopharmacol. 2013;147(1):42-62.

10. Anonymous Rhododendron cinnabarinum Hook. In: Anonymous, editor. New York: Springer; 2007. p. 1.

11. Rezk A, Nolzen J, Schepker H, Albach DC, Brix K, Ullrich MS. Phylogenetic spectrum and analysis of antibacterial activities of leaf extracts from plants of the genus Rhododendron. BMC Complement Altern Med. 2015;15:67.
12. Rezk A, Schepker H, Brix K, Ullrich MS: Assessment of cytotoxicity exerted by leaf extracts from plants of the genus Rhododendron towards epidermal keratinocytes and intestine epithelial cells. Submitted 2015.

13. Nathan P, Law EJ, Murphy DF, MacMillan BG. A laboratory method for selection of topical antimicrobial agents to treat infected burn wounds. Burns. 1978;4(3):177-87.

14. Gu L, Kelm MA, Hammerstone JF, Zhang Z, Beecher G, Holden J, Haytowitz D, Prior RL. Liquid chromatographic/electrospray ionization mass spectrometric studies of proanthocyanidins in foods. J Mass Spectrom. 2003;38(12):1272-80

15. Cserhati T, Forgacs E, Morais MH, Mota T. Liquid chromatography of natural pigments. Biomed Chromatogr. 2000;14(5):281-6.

16. Swiderski A, Muras P, Koloczek H. Flavonoid composition in frostresistant Rhododendron cultivars grown in Poland. Sci Hortic. 2004;100(14):139-51.

17. Cao Y, Chu Q, Ye J. Chromatographic and electrophoretic methods for pharmaceutically active compounds in Rhododendron dauricum. J Chromatogr B. 2004;812(12):231-40.

18. Louis A, Petereit F, Lechtenberg M, Deters A, Hensel A. Phytochemical characterization of Rhododendron ferrugineum and in vitro assessment of an aqueous extract on cell toxicity. Planta Med. 2010;76(14):1550-7.

19. Vallverdu-Queralt A, Jauregui O, Di Lecce G, Andres-Lacueva C, LamuelaRaventos RM. Screening of the polyphenol content of tomato-based products through accurate-mass spectrometry (HPLC-ESI-QTOF). Food Chem. 2011;129(3):877-83.

20. Abu-Reidah IM, Arraez-Roman D, Segura-Carretero A, FernandezGutierrez A. Profiling of phenolic and other polar constituents from hydro-methanolic extract of watermelon (Citrullus lanatus) by means of accurate-mass spectrometry (HPLC-ESI-QTOF-MS). Food Res Int. 2013;51(1):354-62.

21. Ma Y, Kosinska-Cagnazzo A, Kerr WL, Amarowicz R, Swanson RB, Pegg RB. Separation and characterization of phenolic compounds from dryblanched peanut skins by liquid chromatography-electrospray ionization mass spectrometry. J Chromatogr A. 2014;1356:64-81.

22. Lhuillier A, Fabre N, Moyano F, Martins N, Claparols C, Fouraste I, Moulis C. Comparison of flavonoid profiles of Agauria salicifolia (Ericaceae) by liquid chromatography-UV diode array detection-electrospray ionisation mass spectrometry. J Chromatogr A. 2007;1160(1-2):13-20.

23. De Rosso M, Tonidandel L, Larcher R, Nicolini G, Dalla Vedova A, De Marchi F, Gardiman M, Giust M, Flamini R. Identification of new flavonols in hybrid grapes by combined liquid chromatography-mass spectrometry approaches. Food Chem. 2014;163:244-51.

24. Li S, Xiao J, Chen L, Hu C, Chen P, Xie B, Sun Z. Identification of A-series oligomeric procyanidins from pericarp of Litchi chinensis by FT-ICR-MS and LC-MS. Food Chem. 2012;135(1):31-8.

25. Zhao T, He J, Wang X, Ma B, Wang X, Zhang L, Li P, Liu N, Lu J, Zhang X. Rapid detection and characterization of major phenolic compounds in Radix Actinidia chinensis Planch by ultra-performance liquid chromatography tandem mass spectrometry. J Pharm Biomed Anal. 2014;98:311-20.

26. Jaiswal R, Karakose H, Ruhmann S, Goldner K, Neumuller M, Treutter $D$, Kuhnert N. Identification of phenolic compounds in plum fruits (Prunus salicina L. and Prunus domestica L.) by high-performance liquid chromatography/tandem mass spectrometry and characterization of varieties by quantitative phenolic fingerprints. J Agric Food Chem. 2013;61(49):12020-31.

27. Sapozhnikova Y. Development of liquid chromatography-tandem mass spectrometry method for analysis of polyphenolic compounds in liquid samples of grape juice, green tea and coffee. Food Chem. 2014;150:87-93.

28. Torras-Claveria L, Jáuregui O, Codina C, Tiburcio AF, Bastida J, Viladomat F. Analysis of phenolic compounds by high-performance liquid chromatography coupled to electrospray ionization tandem mass spectrometry in senescent and water-stressed tobacco. Plant Sci. 2012;182:71-8.

29. Biesaga M, Pyrzynska K. Liquid chromatography/tandem mass spectrometry studies of the phenolic compounds in honey. J Chromatogr A. 2009;1216(38):6620-6.

30. Zhou H, Liang J, Lv D, Hu Y, Zhu Y, Si J, Wu S. Characterization of phenolics of Sarcandra glabra by non-targeted high-performance liquid chromatography fingerprinting and following targeted electrospray ionisation tandem mass spectrometry/time-of-flight mass spectrometry analyses. Food Chem. 2013;138(4):2390-8. 
31. Ruiz A, Bustamante L, Vergara C, von Baer D, Hermosín-Gutierrez I, Obando L, Mardones C. Hydroxycinnamic acids and flavonols in native edible berries of South Patagonia. Food Chem. 2015;167:84-90.

32. Rockenbach II, Jungfer E, Ritter C, Santiago-Schubel B, Thiele B, Fett R, Galensa R. Characterization of flavan-3-ols in seeds of grape pomace by CE, HPLC-DAD-MSn and LC-ESI-FTICR-MS. Food Res Int. 2012;48(2):848-55.

33. Zhang ZR, Al Zaharna M, Wong MM, Chiu SK, Cheung HY. Taxifolin enhances andrographolide-induced mitotic arrest and apoptosis in human prostate cancer cells via spindle assembly checkpoint activation. PLOS ONE. 2013;8(1):e54577.
34. Watjen W, Michels G, Steffan B, Niering P, Chovolou Y, Kampkotter A, TranThi QH, Proksch P, Kahl R. Low concentrations of flavonoids are protective in rat H4IIE cells whereas high concentrations cause DNA damage and apoptosis. J Nutr. 2005;135(3):525-31.

35. He Z, Xia W. Analysis of phenolic compounds in Chinese olive (Canarium album L.) fruit by RPHPLC-DAD-ESI-MS. Food Chem. 2007;105(3):1307-11.

36. Perestrelo R, Lu Y, Santos SAO, Silvestre AJD, Neto CP, Câmara JS, Rocha SM. Phenolic profile of Sercial and Tinta Negra Vitis vinifera L. grape skins by HPLC-DAD-ESI-MSn: novel phenolic compounds in Vitis vinifera L. grape. Food Chem. 2012;135(1):94-104.

\section{Submit your next manuscript to BioMed Central and we will help you at every step:}

- We accept pre-submission inquiries

- Our selector tool helps you to find the most relevant journal

- We provide round the clock customer support

- Convenient online submission

- Thorough peer review

- Inclusion in PubMed and all major indexing services

- Maximum visibility for your research

Submit your manuscript at www.biomedcentral com/submit 